\title{
Dialectics, Evaluation, and Argument
}

\section{Maurice A. Finocchiaro University of Nevada, Las Vegas}

\begin{abstract}
A critical examination of the dialectical approach, focusing on a comparison of the illative and the dialectical definitions of argument. I distinguish a moderate, a strong and a hyper dialectical conception of argument. I critique Goldman's argument for the moderate conception and Johnson's argument for the strong conception, and argue that the moderate conception is correct.
\end{abstract}

\begin{abstract}
Résumé: Un interrogatoire critique sur l'approche dialectical, qui concentre sur une comparaison des définitions d'argument illatives et dialecticales. Je distingue trois conceptions de l'argument: la modérée, la forte, et la hyper. Je critique l'argument de Goldman qui supporte la conception modérée et celui de Johnson qui support la conception forte, et je prétends que la conception modérée est exact.
\end{abstract}

Keywords: argument, argumentation, argument evaluation, dialectical, dialectics, definitions of argument, illative, informal logic, Ralph H. Johnson, Alvin I. Goldman.

\section{Introduction: Critique of the Dialogue Model}

For several years I have been exploring the nature of the dialectical approach to argument, its relationship to other approaches, its methodological fruitfulness, and its limitations. Although the precise meaning of the dialectical approach is part of the problem, I can say immediately that I mean it in the sense in which it is distinguished from monological or monolectical approaches, and not in the sense it is distinguished from logical and rhetorical approaches; for these two distinctions criss-cross each other, as is obvious from the work of many scholars that is both dialectical and logical (Barth and Krabbe 1982; Blair and Johnson 1987; Woods and Walton 1989). My main motivation stems from the fact that the dialectical approach has become the dominant one in argumentation theory. Now, whenever any approach in any field becomes dominant, there is always the danger that it will lead to the neglect or loss of insights which are easily discernible from other orientations; this in turn may even prevent the dominant approach from being developed to its fullest as a result of the competition with other approaches.

Let us begin with a review of some background results from the relevant literature. One of the best examples of the dialectical approach is a work entitled From Axiom to Dialogue by Else Barth and Erik Krabbe (1982; cf. Barth and Martens 1982). A critical examination of this work reveals that their achievement is not really to demonstrate the necessity to move from the axiomatic to the dialec-

(C) Informal Logic Vol. 23, No. 1 (2003): pp. 19-49. 
tical approach, by reducing the former to the latter; instead the structure of their proof is to demonstrate the equivalence of the methods of axiomatics, natural deduction, and formal semantics to the method of formal dialectics. However, as I have argued elsewhere (Finocchiaro 1995), the proof works both ways, so that the former methods acquire the merits of the latter, and the latter the limitations of the former; and the unintended consequence is that there is no logical difference between the axiomatic and the formal-dialectical method, and their difference will have to be located in some other domain.

Another extremely important result is due to James Freeman's (1991) work on Dialectics and the Macrostructure of Arguments and Francisca Snoeck Henkemans's (1992) work on Analysing Complex Argumentation. They have independently provided a dialectical analysis of complex argumentation, namely arguments where a conclusion is supported by more than just a single reason, either in the sense that two or more distinct reasons are given to support the conclusion, or in the sense that the reason which directly supports the conclusion is itself in turn supported by another reason. Their main accomplishment is to interpret arguments as the result of a hypothetical dialogue between a proponent or respondent and an opponent or challenger, a process during which the opponent asks various kinds of questions. However, as I have also argued previously (Finocchiaro 1995, 193-94; 1999, 195-96), the questions asked are by and large evaluative questions, and so besides explicitly providing an illustration of the power of what might be called the informal-dialogical method, these authors have also implicitly suggested the evaluative dimension of complex argumentation. They may also be seen as having stressed the importance of complex argumentation and suggested that the usual emphasis on simple arguments is an undesirable oversimplification.

A move in this direction (toward evaluation and complexity) has also been independently made by J. Anthony Blair. In a paper entitled "The Limits of the Dialogue Model of Argument" (Blair 1998), he has distinguished thirteen levels of complexity of dialogues depending on the complexity of the argument allowed at each turn of the dialogue; the thirteenth level is the one which is the norm in a scholarly paper or commentary. Blair also distinguishes between what he labels "solo" arguments and "duet" arguments: in solo arguments the respondent and audience are physically absent; their identity may not be known or fixed; and the norms of the discussion are not settled but open to dispute. Then he argues plausibly that to speak of dialogues for complex or solo arguments is metaphorical at best and probably distorting. Blair concludes with some theses that embody both a non-dialogical conception of the dialectical approach and of solo arguments. His words are worth quoting at length:

It would be nice if the term 'dialectical' were reserved to denote the properties of all arguments related to their involving doubts or disagreements with at least two sides, and the term 'dialogue' were reserved to denote turntaking verbal exchanges between pairs of interlocutors. Then I could use this terminology to express the points that (1) all argumentation is dialectical, but 
by no means is all argumentation dialogical, and (2) the dialectical properties of dialogues, and the norms derived from the dialogue model, do not apply to non-dialogical argument exchanges, even though the latter are dialectical too. In other words, both duet arguments and solo arguments are dialectical, but only duet arguments are dialogues. [Blair 1998, 10]

One final explicitly critical contribution deserves mention. Chris Reed and Derek Long have stressed the importance and pervasiveness of what they call "persuasive monologue." A persuasive monologue is not merely a soliloquy, which is "a record of a chain of reasoning" (Reed and Long 1998, 2); nor an internal dialogue, "in which the speaker plays both roles" (ibid.); nor a "turn in dialogue" (ibid.). Instead persuasive monologue has two main characteristics: "firstly, the intuitive "case building' of presenting arguments in support of the thesis" (Reed and Long $1998,3)$; and "secondly, there is the more complex technique of presenting counterarguments to the thesis propounded, and then offering arguments which defeat those counterarguments" (ibid.) Although these authors' main interest seems to be the formal analysis and the computerized modeling of persuasive monologues, the point I would want to stress is that the second clause of their definition refers to replying to objections, and such criticism of counterarguments is a feature which many would not hesitate to call dialectical, in a sense of this word distinct from dialogical.

The upshot of these preliminary remarks is as follows. Proponents of the dialectical approach tend to presuppose a particular concept of dialectics, pertaining to dialogue or turn-taking; and they have produced results implicitly suggesting that dialogue may be dispensable (in favor of either deductive axiomatization or argument complexity and evaluation). Critics of the dialectical approach tend to stress monological argumentation, but in so doing they are quite sensitive to an aspect of argument which is dialectical in a sense other than the dialogical one (a sense pertaining to doubting with two sides and defeating counterarguments). With this literature and these reflections in the background, I now want to examine a particular problem, to try to understand the difference (if any) between a dialectical and a nondialectical approach to this problem, and the implications (if any) of the respective solutions to the question of the relative merits of the two approaches. The problem is that of how argument is to be conceived.

\section{Concepts of Argument}

Let us begin with what may be called the traditional conception of argument, or to be more precise, a version of the standard textbook definition. As many authors have done (Walton 1990, 408-9; Johnson 2000a, 146; Hansen 2002, 264), I too find it useful to quote Copi's definition: "An argument, in the logician"s sense, is any group of propositions of which one is claimed to follow from the others, which are regarded as providing support or grounds for the truth of that one" (Copi and Cohen 1994, 5). 
However, although many of the same authors (e.g., Johnson 2000a, 148) take this to be a structural definition, 1 find it improper and misleading to speak of structure here because the structure involved is too insignificant to merit the name. The traditional concept does indeed define an argument as an ordered set of propositions, but the order introduced is simply that of designating one of the propositions as the conclusion; in other words, a distinction is made among all the propositions in the set, a distinction between the conclusion and the premises. However, such a single partition does not really yield a genuine structure, which for my sensibility would have to have at least two partitions; that is, the minimal order 1 would want before calling it a structure is three propositions interrelated in such a way that one is supported by the second, which is in turn supported by the third. Instead of calling it structural, one might call this aspect of the traditional definition relational.

A second important feature of Copi's definition is the reference to the intention or purpose of the arguer. Again, although many commentators (e.g., Johnson $2000 \mathrm{a}, 148$ ) have denied such a teleological character, it seems obvious to me that when Copi says that the conclusion is claimed to follow from the premises, he is saying that the arguer claims this. And when he says that the premises are regarded as providing support or grounds for the conclusion, he is saying that the premises are so regarded by the arguer; that is, the arguer intends to use the premises to support the conclusion. In short, the purpose of the argument is to justify the conclusion by means of supporting reasons.

I am stressing that according to Copi's version of the traditional definition, an argument has function but no structure. I believe there is a term that conveys both features, namely the term illative, which I adopt from Ralph Johnson (2000a, 150), who adopted it from Blair (1995). This traditional definition may thus be called the illative conception of argument. Illation is the special relationship that holds between premises or reasons and conclusion or thesis; it is not a purely abstract relation, but one that subsists in the mind of the arguer and of anyone trying to understand or evaluate the argument.

Two other versions of the traditional definition are worth mentioning, one more and one less abstract than the illative conception. The more abstract one avoids any reference to purpose and defines an argument simply as an ordered set of propositions partitioned into two subsets. For example, in Choice and Chance, Brian Skyrms stipulates that "an argument is a list of sentences, one of which is designated as the conclusion, and the rest of which are designated as premises" (Skyrms 1966, 1-2). Those scholars who deny the teleological character of the traditional definition are probably thinking of this version, although of course it should not be equated with other versions such as Copi's.

The less abstract (or more concrete) version of the traditional definition adds a rhetorical condition to the illative conception, namely an element of persuasion. This conceives an argument as an attempt to persuade others that a conclusion is 
true by giving reasons in support of it. An example of such a definition coines from Michael Scriven's book Reasoning: "The simplest possible argument consists of a single premise, which is asserted as true, and a single conclusion, which is asserted as following from the premises, and hence also to be true. The function of the argument is to persuade you that since the premise is true, you must also accept the conclusion" (Scriven 1976, 55-56)

These three versions of the traditional conception are importantly different, and constitute a sequence of increasingly more complex and narrow definitions (as one moves from the purely abstract one through the illative one to the rhetorical). But they also share some very important features. All three lack any reference to a complex structure, or structure worthy of the name, as I have already mentioned. And all three lack any reference to dialectical matters, which will be our focus. Thus, let us now turn to what we may call the dialectical conception of argument.

The most natural version of the dialectical conception simply adds an element of criticism of objections to what I have called the rhetorical definition. We thus get that an argument is defined as an attempt to persuade someone that a conclusion is acceptable by giving reasons in support of it and defending it from objections. The best known example of this is the definition found in Johnson's book Manifest Rationality: "An argument is a type of discourse or text-the distillate of the practice of argumentation - in which the arguer seeks to persuade the Other(s) of the truth of a thesis by producing the reasons that support it. In addition to this illative core, an argument possesses a dialectical tier in which the arguer discharges his dialectical obligations" (Johnson 2000a, 168).

There is no time here for me to repeat or summarize the various clarifications that have been made to Johnson's definition by Johnson (2002a; forthcoming) himself as well as by Trudy Govier (1998; 1999b; 2000), David Hitchcock (2002a), Hans Hansen (2002), and others (Groarke 2002; Leff 2000; Tindale 2002; Rees 2001; Wyatt 2001), although I will say a little more later in the context of my analysis of Johnson's argument (section 6, below). However, I have already implicitly incorporated many of these clarifications when I gave my own formulation, before exemplifying it with Johnson's definition. In any case, a few remarks are in order and may be relatively novel.

One thing I would want to point out is that by calling illative core the complex of conclusion and supporting reasons, Johnson suggests that the illative core is more fundamental than the dialectical tier. Now, this may very well be true; but it may not be. I would regard it as open question. Of this more presently. However, in order not to beg this question, I shall speak of the illative tier or component rather than core.

Another question I would want to ask is, why call dialectical tier or discharge of dialectical obligations such things as examination of alternative positions and reply to objections? What is the concept of dialectics inherent in such a termino- 
logical decision, and how is such a conception to be justified? Is it enough to do some hand waving in the direction of Plato's dialogues? Johnson's concept of dialectics is the one inherent in the following explicit statement: "that argumentation is dialectical means that the arguer agrees to let the feedback from the other affect her product. The arguer consents to take criticism and to take it seriously. Indeed, she not only agrees to take it when it comes, as it typically does; she may actually solicit it. In this sense argumentation is a (perhaps even the) dialectical process par excellence" (Johnson 1996, 107; cf. Johnson 2000a, 16I; cf. Finocchiaro 1999, 195).

Third, besides Johnson's references to written text, argumentative practice, purpose, persuasion, and truth, it is important to note the reference to both the illative and dialectical components or tiers. This implies that a text with an illative tier but without a dialectical one is not strictly speaking an argument (as some of Johnson's critics have pointed out, thus yielding an alleged reductio ad absurdum of his definition); but Johnson himself prefers to say that such a text "does not fit the paradigm case of argument" (Johnson 2002a, 316).

In the present context, however, the point I want to stress is that there is a natural way to moderate Johnson's double requirement by disjoining the two conditions, in the sense inclusive disjunction. We thus get the following conception: an argument is an attempt to persuade someone that a conclusion is true by giving reasons in support of it or defending it from objections. This is a weaker dialectical conception than Johnson's definition, but it still is importantly dialectical because it does call attention to the potential need to discharge one's own dialectical obligations, and because the inclusive disjunction obviously allows for cases where the argument contains both illative and dialectical tiers.

Such a more moderate dialectical conception has in fact been advanced by some scholars. If I understand him correctly, I believe AIvin Goldman does this in his book Knowledge in a Social World. He explicitly allows for what he labels monological argumentation besides dialogical argumentation, as can be seen from this passage:

If a speaker presents an argument to an audience in which he asserts and defends the conclusion by appeal to the premises, I call this activity argumentation. More specifically, this counts as monological argumentation, a stretch of argumentation with a single speaker... I shall also discuss dialogical argumentation in which two or more speakers discourse with one another, taking opposite sides of the issue over the truth of the conclusion" (Goldman 1999, 131).

And for Goldman, a crucial principle governing dialogical argumentation is this: "when there are existing or foreseeable criticisms of one's main argument, a speaker should embed that argument in an extended argumentative discourse that contains replies to as many of these (important) criticisms as is feasible" (Goldman 1999, 144). 
We thus have two versions of the dialectical conception of argument, a stronger one exemplified by Johnson that regards the dialectical or critical tier as necessary for any argument, and a moderate one exemplified by Goldman that makes the dialectical or critical tier essential for one type of argument but not for all. Although these two versions of the dialectical conception are the most common and natural ones, there is actually a third version that deserves discussion and may be regarded as more strongly dialectical than Johnson's conjunctive version. This hyper dialectical conception would define an argument as an attempt to justify a conclusion by defending it from objections. According to this conception, replying to objections is both a sufficient and a necessary condition to have an argument; whereas for Johnson's strong dialectical conception, replying to objections is necessary but not sufficient; and for Goldman's moderate dialectical definition, replying to objections is sufficient but not necessary.

Unintuitive as it may sound, the hyper dialectical conception has been advanced by some scholars. In a 1980 book by the present author, entitled Galileo and the Art of Reasoning, in the context of a number of theoretical considerations, we find the following theoretical definition: "We may then say that an argument is a defense of its conclusion from actual or potential objections" (Finocchiaro 1980, 419). More recently, in her review of Johnson's Manifest Rationality, Agnès van Rees has criticized his definition of argument for being insufficiently dialectical. Here are her revealing words: "According to this definition, producing reasons and discharging one's dialectical obligations are two different things. But in actual fact, if the notion of argument is indeed to be rooted in the dialectical practice of argumentation, the two should coincide. In a truly dialectical account, argument per se would be defined as an attempt to meet the critical reactions of an antagonist, that is, to take away anticipated objections and doubt" (Rees 2002, 233). And besides these two explicit formulations, the hyper dialectical definition has a memorable, emblematic, and brilliant illustration; that is, an argument by Alan M. Turing published in 1950 in the journal Mind, advocating that machines can think based primarily on a critique of nine objections to this conclusion.

Once again, however, despite the differences among these three versions of the dialectical conception, my focus will be on what they have in common. Their common element is an emphasis on replying to objections or to criticism. It is such a dialectical component that provides an instructive contrast to the illative conception. And it is this dialectical tier that $l$ want to understand better and evaluate. With such an aim, the next step will be to examine various arguments that have been advanced in favor of the dialectical conception of argument.

\section{Arguments for the Dialectical Definition}

What we are faced with now is an exercise in informal logic and critical thinking, for what we want to do is to identify, interpret, reconstruct, analyze, evaluate, and criticize the arguments for the dialectical conception of argument. I shall focus 
explicitly on arguments advanced by Johnson and by Goldman, but implicitly underlying my examination will be arguments suggested by the present speaker in the above mentioned 1980 book, and by John Stuart Mill in his essay On Liberty. There will be no time or space for me to elaborate my 1980 arguments for the hyper dialectical conception, or to search for Rees's argument for the same conception, or to examine Mill's arguments, which will have to be done on some other occasion. However, one additional remark on Mill is worth making.

Mill has already been injected into this discussion by an insightful interpretive hunch of Hansen $(2002,271)$, when he spoke of Mill's "dialectical method" and quoted a crucial passage from Mill's essay On Liberty. This reference led me to read Mill, and I discovered that the second chapter of his essay contains some of the strongest and most instructive arguments. Mill is ostensibly arguing for the thesis that freedom of expression of opinion is essential in the quest for knowledge and search for truth, but the connection with our topic becomes evident when we see that a key part of freedom of expression involves the freedom to express dissenting opinions, which in turn involves the toleration (and indeed the encouragement) of counterarguments; thus truth and knowledge require the understanding and criticism of counterarguments. We can get a glimpse and flavor of the relevance and importance of Mill's considerations from the following striking assertion: "When we turn to subjects [such as] morals, religion, politics, social relations, and the business of life, three-fourths of the arguments for every disputed opinion consist in dispelling the appearances which favor some opinion different from it" (Mill, On Liberty, ch. ii, par. 23; 1965, 286-87).

For now, let me focus on an argument that has been advanced by Goldman, or at least which I extract from Goldman; it deserves discussion because of its novelty. What he intends to justify is "a general thesis about critical argumentation and the probability of acquiring truth... that lively and vigorous debate is a desirable thing"(Goldman 1999, 144), desirable in the sense that it "has positive veritistic properties" (Goldman 1999, 146). In other words, critical argumentation is likely to lead to the truth. The connection between this conclusion and the dialectical conception of argument may be elaborated as follows. Goldman $(1999,132)$ says that "critical argumentation is an attempt to defeat or undercut the proffered argument," and he contrasts it to "proponent argumentation [which] is a defense of the asserted conclusion by appeal to the cited premises" (Goldman 1999, 132). To this I add that if critical argumentation is a veritistically good thing, then it will also be desirable for the special case when the proffered argument is a critical argument, and so a reply to the critical argument is called for. Such a reply is precisely what the dialectical conception of argument stipulates.

Next, Goldman distinguishes at least three subtypes of critical argumentation, one that denies the truth of a premise, a second that questions the link between premises and conclusion, and a third one which he calls "presenting a defeater" (Goldman 1999,140). Then he formulates his argument for the special case of the 
latter, which is a notion he adopts from John Pollock (1986, 33-39; cf. Goldman $1999,138-39,139 \mathrm{n} .11,144-45)$ and may be explained as follows. Given an argument with premises $\mathrm{P}-1$ through $\mathrm{P}-\mathrm{n}$ and conclusion $\mathrm{C}$, a defeater is a critical argument with the same premises plus one additional special premise $\mathrm{D}$ and conclusion not-C. A simple example given by Goldman himself is this: consider the argument that it will probably rain tonight because it was so stated last night in the local weather forecast of a reliable news medium; a defeater of this argument would be the counterargument that it will probably not rain tonight because although it was so stated last night in the weather forecast of a reliable local news media source, it was also stated this morning by the same source that the forecast had changed and the new prediction was fair weather tonight.

I will label Goldman's argument the "truth-in-evidence" argument because it is based on a premise which he himself calls the truth-in-evidence (TEP) principle; it asserts the following: "a larger body of evidence is generally a better indicator of the truth-value of a hypothesis than a smaller, contained body of evidence, as long as all the evidence propositions are true and what they indicate is correctly interpreted" (Goldman 1999, 145). He points out that this principle is an epistemic version of the requirement of total evidence discussed in a methodological context by Rudolph Carnap $(1950,211)$ and Carl Hempel $(1965,64-67)$. Goldman also says that the principle is a generalization of Bayes' theorem. Although these are reasons of sorts, and although the principle has some inherent plausibility, Goldman $(1999,145-46)$ confesses that "I have no proof of this postulate."

But how does this principle support his conclusion that critical argumentation, or at least defeater presentation, is conducive to truth? Clearly, a defeater argument does encompass a larger body of evidence than the argument being criticized. So, Goldman's premise is indeed relevant.

But is it sufficient? He attempts to articulate such sufficiency by commenting on the two provisos incorporated into the principle. The condition of truth for the evidence propositions could be somewhat relaxed (he says) by requiring merely that they be justified. The other condition was that what the evidence propositions indicate be correctly interpreted; this seems to mean that it be correct to claim that the premises of the defeater argument imply or support the denial of the conclusion of the original argument. And Goldman himself suggests that in real-world cases such an implication would be itself controversial. The upshot of his articulation seems to be that in order for a defeater argument to have positive veritistic properties in accordance with the truth-in-evidence principle, the defeater has itself to be a good argument, namely have true or justified or acceptable premises, and these premises have to really support its own conclusion; but in realistic situations such goodness would be controversial.

Goldman seems to be aware of such difficulties, for despite his articulation and elucidation, what he claims about the premise-conclusion link of his argument is very modest. He says: "Suppose ... that (TEP) is correct. May we derive from it 
the veritistic desirability of engaging in defeater argumentation? In other words, does (TEP) imply that defeater argumentation usually has positive V-value? Although I shall not attempt to prove it, I suspect that this does follow" (Goldman 1999, 146).

Another difficulty that could be raised stems from the fact that Goldman intends his argument, which is specifically formulated in terms of defeater arguments, to apply to other cases of critical argumentation. However, its relevance to these other cases is questionable.

But to end on a more positive note, there are other valuable aspects of an argument besides such properties as truth of premises and validity of inference, or acceptability, relevance, and sufficiency of premises. Some of the additional values are what might be called suggestiveness or fruitfulness and novelty or originality. And along these dimensions, I would rate Goldman's truth-in-evidence argument very highly.

\section{Johnson's Argument: Its Illative Tier}

Let us now examine Johnson's argument for the dialectical conception. As one would expect, his argument possesses an illative component as well as a dialectical tier, and the latter contains both replies to objections and criticism of alternative positions. The main alternative is what he calls the structural definition of argument, which (as suggested above) is not really structural and should rather be labeled the illative conception of argument.

One of Johnson's key supporting reasons I locate in passages where he makes statements such as the following:

Philosophers and others for whom argumentation is the principal methodology routinely include in their own arguments a section in which they voice and then deal with objections to their position. ... If ... we look at the best practices of those who have the most at stake in this process, philosophers and logicians who have a vested interest in this practice, we will find that their arguments always take account of the standard objections. . . A Arguments with a dialectical tier are found in nonacademic discourse as well. [Johnson 2000a, 165-66]

Here we have an empirical argument, which some would call an induction by enumeration, and others more simply a generalization argument or an inductive generalization. Although in his book Johnson does not himself categorize this argument in this manner, I am encouraged to advance this interpretation by the fact that in one of his papers he does speak favorably of the "empirical turn" (Johnson $2000 \mathrm{~b}, 14-15$ ). Moreover, such a strand of argument is also found in other dialectically inclined authors. For example, Goldman, after defining an "extended argumentative discourse" as a series of nested arguments that present and answer objections, states that "in science, scholarship, law, and other polemical realms, extended argumentative discourses are the norm. Scholars are expected to report 
existing findings and literature that form the basis of predictable objections" (Goldman 1999, 144).

Also reminiscent of such an empirical argument is Mill's assertion, quoted earlier, that three-fourths of arguments involving human affairs consist of attempts to reply to objections.

If and to the extent that Johnson's case for the dialectical conception of argument includes an empirical inductive generalization, then its evaluation would have to deal with questions such as the following. For example, if indeed the best examples of arguments by philosophers have a dialectical tier, should our conclusion be that good philosophical arguments have a dialectical tier, or that all philosophical arguments have a dialectical tier? In other words, that all philosophical arguments ought to have a dialectical tier, or that they do have a dialectical tier? Can our conclusion be that good arguments in general (whether philosophical or not) have a dialectical tier; in other words, from a sample containing information about philosophical arguments, how can we reach a conclusion about arguments in general? Do we not also need data about the characteristics of arguments in other disciplines, such a science and the law, as Goldman indicates? But if we gather such data about, for example, science, such scientific arguments that thus have a dialectical tier may happen to be those in special domains of scientific activity, such as in the context of peer discussion at the frontiers of research or in periods of scientific revolution; what are we then to say about other domains such as the context of scientific justification or the context of pedagogy or periods of normal science? And if indeed, as Mill states, three-fourths of arguments have a dialectical tier (indeed only this tier), should not the conclusion be qualified to make it a statistical rather than a universal generalization? And what are we to say about the other one-fourth of arguments? Finally, if we take seriously the possibility of an empirical inductive confirmation of the dialectical conception of argument, does not the above-mentioned evidence appear as merely anecdotal? Should we not attempt to devise more systematic and controlled tests or data gathering?

Some scholars have indeed undertaken such attempts. 1 am thinking of Hitchcock's (2002b) sampling of scholarly arguments to test his theory of inference; of David Perkins's (1989; Perkins et al. 1983) studies of the difficulties in everyday reasoning; and of the present author's examination of arguments in Galileo's Dialogue on the Two Chief World Systems (Finocchiaro 1980; 1994). I believe that by and large the relevant parts of such inquiries do support the thesis of the dialectical nature of argument. In fact, it was in the context of such an empirical investigation that the present writer drew the conclusion mentioned earlier and labeled the hyper dialectical conception of argument, namely "that an argument is a defense of its conclusion from actual or potential objections" (Finocchiaro 1980 , 419).

Although such an empirical approach has also been appreciated or advocated by other philosophers (Barth 1985; Krabbe 2000,4), it is unlikely that most phi- 
losophers will have much interest in using such empirical argumentation to support their theories of argument; so let us go on to more theoretical and conceptual considerations, especially since we find such supporting reasons in Johnson's book.

A second supporting reason in Johnson's illative tier is a premise about the nature of the process of arguing. He states that "the process of arguing includes, by its very nature, feedback from the Other. Nor does the process of arguing end there. Also included as part of the process must be the response by the arguer to those objections and criticisms, as well as any revisions made by the arguer" (Johnson 2000a, 157). If we recall that for Johnson an argument is the so-called "distillate of the practice of argumentation" (Johnson 2000a, 168), then the relevance and sufficiency of this premise becomes obvious. What about its acceptability? Here we have to remember that Johnson is talking about one of several meanings of the word argue or arguing; and certainly for this particular meaning it is unobjectionable and true that the process of arguing does have such a dialectical component.

However, this claim about the nature of the process of arguing is almost analytically true. So an unfriendly evaluator might at this point raise the possibility that Johnson's argument from the nature of the process of arguing begs the question. But a more friendly critic might point out that the function of this particular argument is to articulate a necessary connection between the process of arguing and the concept of argument, and the articulation of such analytic relations is a normal part of any theorizing; thus it is no defect of a theory of argument that at some point it has to explain the links among various elements of its conceptual structure. However, such friendly criticism may have a consequence that suggests some possible revision by the arguer. That is, some arguments do not have rational persuasion as their telos, but rather the analytic elucidation of conceptual relations; and this is one of those arguments. But if we defend this argument in this manner from the criticism that it begs the question, then one has to revise the teleological rhetorical aspect of Johnson's definition. This could be done by stating the definition by saying that an argument is an attempt to justify a conclusion instead of saying that it is an attempt to persuade others that a conclusion is true.

Another way out might be to say that here both the friendly critic and the unfriendly evaluator are committing the fallacy of straw man, when they interpret these considerations about the nature of the process of argument as an argument in support of Johnson's definition; after all, he does not himself explicitly label them an argument. This denial of argumentative status would by itself be unproblematic, but it would begin to weigh if added to the previous unfriendly evaluation that Johnson's empirical inductive generalization was anecdotal. For one reply to that evaluation might have been that his empirical considerations should not be interpreted as a real or full-fledged empirical argument susceptible of evaluation in terms of the adequacy, variety, and representativeness of the sample used; 
and then we would be saying that neither the empirical considerations nor the conceptual ones were arguments. However, this consequence would not be fatal because there is at least one passage in Johnson's book that seems to advance a supporting reason as explicitly as the practice of argumentation allows. To this we now turn.

This is the passage where Johnson tries to ground the dialectical tier on the telos of rational persuasion. In his own words, "because the practice exists to achieve rational persuasion of the Other as a rational agent, the practice must also be dialectical" (Johnson 2000a, 160). To avoid straw-man problems, 1 quote this argument verbatim:

Because the arguer's purpose is rational persuasion, a second tier is required as well. Why? I have shown that the practice of argumentation presupposes a background of controversy. The first tier (the illative core) is meant to initiate the process of converting Others, winning them over to the arguer's position. But they will not easily be won over, nor should they be, if they are rational. The participants know that there will likely be objections to the arguer's premises. Indeed, the arguer must know this, so it is typical that the arguer will attempt to anticipate and defuse such objections within the course of the argument. If the arguer does not deal with the objections and criticisms, then to that degree, the argument is not going to satisfy the dictates of rationality; more precisely, to that very degree the argument falls short of what is required in terms of structure-never mind the content; that is, the adequacy of the response to those objections. For those at whom it is directed, those who know and care about the issue, will be aware that the argument is open to objections from those who disagree with its reasons, conclusion, and-or reasoning. Hence, if the arguer wishes to persuade Others rationally, the arguer is obligated to take account of those objections and opposing points of view. To ignore them, not to mention them, or to suppress them-these could hardly be considered the moves of someone engaged in the process of rational persuasion; thus, the process of persuasion must include a second-dialectical-tier in which objections and criticism are dealt with. [Johnson 2000a, 160; cf. Johnson 2000a, 165]

This is a plausible argument, but I should like to point out that there are two, and not just one, final premises: the claim that the purpose of the argument is rational persuasion, and the claim that the process of argumentation occurs in a context of controversy. And the latter claim is both crucial and independent of the first. But as John Stuart Mill (On Liberty, ch. 2, par. 23; 1965, 286) pointed out, in Euclidean geometry rational persuasion is achieved with just the illative tier, without any need of dealing with objections. Hence, the dialectical tier is not a consequence of just the telos of rational persuasion, but of this telos plus the controversial origin of argumentation.

In other words, Johnson gives the impression that the third reason of the illative tier of his argument for the dialectical conception of argument is the telos of rational persuasion. This impression is misleading because if this reason were the 
only premise it would be insufficient and because in fact Johnson himself combines it with the premise about controversial origin.

I suspect that Johnson's reaction to this criticism would be to insist that controversy is presupposed by all argumentation and to regard geometrical proofs as not arguments but mere inferences or entailments. This move would strike me as arbitrary insofar as Euclidean geometrical proofs are typically attempts to persuade oneself or others of the truth of the theorem in question by rational means. Moreover, the move would be questionable from the point of view of Johnson's own principle of vulnerability because the restriction of the domain to that of controversial situations tends to make the conclusion true by definition; that is, the dialectical tier becomes necessary as an immediate consequence of the controversial context. Then this third reason of Johnson's illative tier would basically reduce to his second reason.

I believe the way to remedy this difficulty would be to revise the conclusion of Johnson's argument by weakening the requirement of the dialectical tier. For example, instead of being regarded as a necessary condition to have an argument, the dialectical tier might be regarded as a sufficient condition. This would amount to replacing the conjunctive version of the dialectical conception with the disjunctive one mentioned earlier.

\section{Johnson's Argument: Its Criticism of Alternative Positions}

So far we have examined the illative tier of Johnson's argument for his dialectical conception of argument. We have identified, analyzed, evaluated, and criticized three supporting reasons. Let us now go on to examine the dialectical tier of his argument. This tier consists of two parts, criticism of the alternative traditional conception of argument, and explicit replies to explicit objections to his definition. The criticism of alternatives can be easily subsumed under the notion of reply to objections, by regarding that criticism as a reply to the objection that the traditional conception of argument is adequate (and constitutes an alternative to the dialectical conception); but it is useful to treat the two parts separately, as Johnson does explicitly in his book.

Let us begin with a criticism that I have implicitly already examined and so can be dealt with relatively briefly. According to Johnson, "argument has its structure (reasons in support of a thesis, or premises plus conclusion) because of the purpose it serves-rational persuasion. A significant limitation of the structural view is that it ignores this important aspect-purpose or function. The moral of the story is that if a satisfactory conceptualization of argument is to be developed, the purpose or function of the discourse must be referred to" (Johnson 2000a, 148, cf. 167). But earlier I pointed out that, although the purely abstract version of the traditional definition does lack any teleological aspect, the illative conception (such as Copi's) is teleological insofar as it does make the aim of argument the justifica- 
tion of the conclusion by means of supporting reasons. Although justification is indeed different from persuasion, this only means that the illative conception attributes to argument a purpose different from the purpose attributed to it by Johnson's dialectical conception. Now, this conception (and even the rhetorical one) may very well be correct that the purpose is persuasion, and the illative conception incorrect that it is justification, but it seems unfair to criticize the latter for conceiving argument as purely structural without function.

A second criticism advanced by Johnson (2000a, 147) is that "the traditional view...must ultimately fail because it does not distinguish argument from other forms of reasoning." He discusses three problematic forms of reasoning: explaining, instructing, and making an excuse. This criticism would be relevant and strong if this claim of confusion were true. But it is not. An analysis of Johnson's supporting critical argument will show this.

Johnson $(2000 a, 146)$ says, "I offer reasons in support when I explain, 'The reason that your car won't start is that you have a dead battery, and also the starter is defective'. Here I am supporting one claim (your car won't start) by another (you have a dead battery) and another (your starter is defective)." This example and others given by Johnson involve a misconception of the notion of support used by the illative definition. In this example, the supporting reasons are not the ones mentioned but rather the observational reports (not mentioned) that after turning the ignition key nothing happened; the mentioned reasons are the causes offered to explain the observed fact. Correspondingly, in the quoted text, the claim that your car won't start does not function as a conclusion but rather as a presupposition or premise of an argument aiming to support the causal claim.

Besides this misunderstanding or misrepresentation of the notion of support used by the illative conception, Johnson's critical argument may involve an equivocation on the term reason. Admittedly a reason can mean a premise helping to establish a controversial conclusion in an argument, or it can mean a cause or explanation helping to account for why a given non-controversial claim is true. So it would be correct to say that one offers reasons when one explains, in one sense of reasons, but not that one offers reasons in support when one explains. Thus, here it may be the critic (and not the proponent of the illative view) who is failing to distinguish argument from explanation.

Johnson's remarks about the other forms of reasoning suffer from similar difficulties. He says, "I offer reasons when I instruct, "If you want to get the best light for this shot, you are going to have to use a XDX-1000 filter combined with...' Here I offer a reason (you are going to have to use a XDX-1000 filter) as support for the claim (if you want to get the best lighting), but the function of the discourse is not to persuade anyone that the claim is true" (Johnson 2000a, 146). Once again, there is no relationship of illative support between the two clauses, and there are not even two distinct claims; rather we have a single claim about a means-end connection between two things. 
Johnson $(2000 \mathrm{a}, 146)$ also says, "I offer reasons when I make an excuse, 'I can't go to the show tonight because I have to study for my exam tomorrow'. Here we have the structure of an argument as defined, but that is not sufficient to qualify it as an argument." I would counter that here we are in the domain of motivation, which is subsumable under the general concept of explanation, although it is also useful to treat it as an important special case. That is, one meaning of reason is that of motivation for an action. Clearly the quoted example is an explanation (of the speaker's not going), not an argument trying to persuade anybody that the speaker is not going. But this is an interpretation reached in the light of the illative conception, which clearly has the resources to say that the need to study is the motivating reason why one is not going, not the evidence proving that one is not going.

A third criticism advanced by Johnson is really a particular case of the second but deserves separate discussion and special attention. It claims that the illative conception presupposes an inadequate conception of a particular kind of reasoning, namely inference. This inadequacy has three overlapping aspects. First, the illative conception tends to conflate three forms of reasoning that ought to be distinguished, namely implication, inference, and argument (Johnson 2000a, 9395). Second, it conceives the illative core in terms of a model that ought to be discarded, namely what Johnson calls "the $(\mathrm{P}+\mathrm{l})$ model, the view that an argument should be seen as consisting of a set of premises, plus an inference from them to the conclusion. The inference is typically represented as a bridge or a link from the premises to the conclusion" (Johnson 2000a, 166-67). Third, it fails to properly distinguish between argument and inference (Johnson 2000a, 177-78).

Much of this criticism is insightful and raises important issues. The key merit is to point out that the illative conception of argument has not been embedded in a wider theory of reasoning that would define, distinguish, and interrelate such concepts as reasoning, argument, inference, implication, and explanation. However, the effectiveness of this criticism is limited by the fact that the dialectical conception of argument, or more generally, Johnson's own pragmatic theory of argument, has also not been embedded within a more comprehensive theory of reasoning. He himself constantly reminds us that the aim of a theory of argument is more narrow than that of a theory of reasoning, and that while the articulation of a theory of reasoning remains a desirable goal, it was not within the scope of his work on the theory of argument. Thus the crucial question is whether the theory of reasoning groped toward or adumbrated by Johnson's dialectical conception is more adequate than that presupposed by the traditional illative conception.

With this aim in mind, I would point out some inadequacies in Johnson's account, besides the ones discussed in connection with the previous criticism involving the relationship between argument, support, reasoning, and explanation (which would also be relevant to the present point). Johnson (2000a, 94) defines implication as "a logical relationship between statements or propositions, in which one follows necessarily from the others"; and he gives the following paradigm 
example: if it is true that if $P$ then $Q$ and that if $Q$ then $R$, then it is true that if $P$ then $R$. He gives this definition and illustration in a passage where he also defines and illustrates inference and argument, with the aim of showing how to distinguish and interrelate these three forms of reasoning. However, it seems to me that implication so defined is not a form of reasoning at all; it is an abstraction and not a form of mental activity. He is not defining implication as what might be called deductive reasoning, which instead is subsumed under his definition of inference as a special case; instead he is defining implication in a way that places it outside the domain of reasoning altogether.

In another passage, where he focuses merely on the distinction between inference and argument, he seems to come close to placing argument itself outside the domain of reasoning. In a summary extolling the advantages of the pragmatic approach, he says that one of these advantages is that "we can begin to get a handle on differentiating between arguments and inference. Arguments, as I have shown, are outcomes within the practice that are dialectical in nature and characterized by manifest rationality. What is an inference? In chapter 4 , I presented inference as in one important sense something that happens in the mind, an activity perhaps spontaneous, perhaps calculated, by which the mind moves from one thought to another" (Johnson 2000a, 177-78). After pointing some similarities, he stresses the following difference: "an inference can be what it is while remaining within the mind of the inferrer; this is not true of argument. One way of drawing this contrast is to say that inferring is monolectical, whereas arguing is a dialectical process. Moreover, argument must be seen within the practice of argumentation, but no comparable requirement exists for inference" (Johnson 2000a, 177-78). The only point I want to make here is that by conceiving an argument as a dialectical process that subsists within the practice of argumentation and cannot remain within the mind of the arguer, Johnson seems to be saying that argument is not a form of reasoning; to be sure it originates in reasoning, but to become argument it has to metamorphosize into non-reasoning. Now, all this may be adequate, sound, and correct from various points of view, but it is clear that we need more than a theory of reasoning; the theory of argument would need to be embedded in something like a theory of action, or a theory of speech acts, or a theory of social interaction.

There is at least one other criticism which Johnson advances against the illative conception, namely its "failure to give an adequate representation of the dialectical character of argumentation" (Johnson 2000a, 165). I hesitate to include this point under the heading of criticism of alternatives, in the dialectical tier of Johnson's own argument; for there seems to be some circularity or question-begging in objecting to a position $\mathrm{P}$ by saying that it fails to describe the matter at hand the way its alternative $Q$ does; in fact this failure is guaranteed by P's being an alternative to $Q$ and is an immediate consequence of that fact. In short, to point out this sort of thing is part of the clarification or elucidation of the two positions. However, Johnson is explicit that he regards this as a "limitation" of the traditional 
conception of argument, and so it deserves some attention. Moreover, it will turn out that the examination of this criticism is useful from a methodological, metalogical, or meta-theoretical point of view.

As one might expect, to justify this criticism Johnson elaborates an argument trying to show that arguments must have a dialectical tier. But this argument is and can only be one of the positive reasons supporting his dialectical conception; that is, one of the elements of the illative tier of his argument. In fact, he repeats the third reason discussed above, namely the one trying to establish that the telos rational persuasion implies the necessity of the dialectical tier. Clearly, here I need not repeat my own criticism of that reason. Instead, I want to elaborate a metatheoretical point.

I want to stress that a positive reason of the illative tier has become a critical reason of the dialectical tier. I believe this could always happen. In fact, consider the illative tier R-1 through R-n of an argument whose conclusion is P; and consider that part of the dialectical tier consisting of various criticisms $\mathrm{C}-1$ through $\mathrm{C}$ $\mathrm{n}$ of alternative $\mathrm{Q}$. Now, if and insofar as any one supporting reason is relevant and sufficient, then it would be more or less true to say that, for example, if R-n is true then $\mathrm{P}$ is also true. Moreover, if and insofar as the various criticisms are cogent, then it would be approximately correct to claim that, for example, if $\mathrm{C}-\mathrm{n}$ is true then $Q$ is false; indeed any particular criticism of $Q$ can be phrased in this manner, for that is what makes it a criticism. Next, note that the fact that $P$ and $Q$ are alternatives means that they are at least contraries (though they need not be contradictories), so that, for example, if $P$ is true then $Q$ is false. Finally, putting together the three claims expressed in my last three sentences, we get that if $R-n$ is true then $\mathrm{Q}$ is false, and hence that $\mathrm{R}-\mathrm{n}$ is a criticism of $\mathrm{Q}$; but $\mathrm{R}-\mathrm{n}$ was one of the supporting reasons in the illative core, and so any such reason can generate a criticism in the dialectical tier.

My final comment here is that not all criticisms of alternatives are or need be dialectical rephrasings of illative supporting reasons. For example, Johnson's first three criticisms are not like that. Thus in discharging one's own dialectical obligations, it seems important to distinguish between criticisms that are independent of the illative tier and criticisms that are not. Only the independent criticisms would seem to add anything new to the argument, whereas the dependent ones may be useful rhetorically or pedagogically but add little to the logical strength of the argument. And this was the methodological, meta-theoretical lesson I wanted to elaborate.

\section{Johnson's Argument: Replies to Objections}

I have been analyzing Johnson's argument in favor of the dialectical conception in light of his own definition. To complete the analysis there remains to examine the second part of its dialectical tier, consisting of his explicit replies to objections. In his book Manifest Rationality, he lists, numbers, and discusses five objections. 
The first objection (Johnson 2000a, 169-71) is that the definition is too restrictive because it disqualifies from the category of arguments discourses that lack a dialectical tier. Johnson's reply is that his definition is indeed restrictive insofar as it does imply this disqualification, but it is not excessively restrictive because this restriction is quite proper. The restriction is proper because it focuses attention on the paradigm and central instances of argument, rather than on the derivative cases that might be called "proto-arguments."

My criticism of this reply is that Johnson's definition is indeed too restrictive because the desired redirection of focus can be accomplished equally well by the moderate, disjunctive version of the dialectical conception. Recall that that conception states that an argument is an attempt to justify a conclusion that gives reasons in support of it and/or defends it from objections.

The second objection (Johnson 2000a, 171-73) is that the dialectical tier is unnecessary in the definition of argument because the work it does could be accomplished in other ways: for example, one could make the dialectical tier part of the normative requirements of a good argument; or part of the definition of such more complex discourses as extended arguments, or cases, or supplementary arguments, or full-fledged arguments, and the like, as distinct from mere arguments or ordinary arguments. Johnson's reply is that the first criticism would have difficulties distinguishing between arguments that are bad insofar as they lack a dialectical tier, and arguments that are bad insofar as their dialectical tier fails to reply effectively to objections. Similarly, the second criticism would lead to the question, when is it enough to give an ordinary argument and when is it necessary to present an extended argument?

I agree that it is important to distinguish between the factual existence of a dialectical tier and the evaluative adequacy of it, and so it may be impossible to go through with the suggestion that the question of the dialectical tier belongs wholly to the theory of assessment, and can be removed from the theoretical problem of definition. However, regarding extended, supplementary, or full-fledged arguments, I do not see any difficulty, and that part of this objection seems to me to reinforce the moderate, disjunctive definition.

The third objection is that the definition is circular because it defines argument in terms of argumentation, among other things (Johnson 2000a, 173; cf. Hitchcock $2002 \mathrm{a}, 289$ ). Johnson replies by admitting that there is a slight circularity, but claiming that the circularity is not vicious or objectionable. I agree with him, in part because I would add that the reference to argumentation is not necessary. In fact, my formulation of the three versions of the dialectical conception avoids such reference, without I believe any loss of generality, at least from the point of view of the contrast between the illative and the dialectical conceptions.

However, another comment is in order. Even if we eliminate mention of argumentation in the wording of the dialectical conception of argument, this eliminates only a potential internal circularity; but this does not avoid what might be called a 
potential external circularity, that is a circularity in the justification of the definitional claim. In fact, we saw earlier that one of Johnson's supporting reasons in the illative tier of his argument was the one based on the nature of the process of arguing; that that argument could be criticized as begging the question; that that criticism could be answered only by making a revision in the definition; and that the revision was to broaden the concept to include justifications that did not aim at rational persuasion but at conceptual clarification.

The fourth objection is that the definition is not novel because it is similar to that advanced by Stephen Toulmin, who used the notion of rebuttal (Johnson 2000a, 173-74; cf. Toulmin 1958, 101). Johnson replies that his definition is indeed similar to Toulmin's, but has some novelty insofar as it is a generalization of it. I agree that Johnson's definition has considerable originality, vis-à-vis Toulmin's. Thus, we might say that the objection is false. However, I believe another issue needs to be raised here.

That is, is this objection relevant? And if it is, why is it relevant? Neither the dialectical nor the illative conception of argument says anything about novelty. Nor do the traditional or Johnson's theories of assessment. In particular, his definition speaks of the truth of the conclusion, and it is the conclusion's truth that needs to be supported with reasons and dialectically defended from objections; it is not the conclusion's novelty or originality. In short, if this fourth objection were true, namely, if Johnson's definitional conclusion were not novel, why would that be a problem? I do not have an answer to this question, although my intuition tells me that such an objection is relevant, that novelty is important, and so that this is an important question.

The fifth and last objection discussed in Johnson's book is that the problem addressed by the definition is one of "just semantics" (Johnson 2000a, 174-75) because the word argument has many meanings, and so it is arbitrary to choose or invent one particular meaning. Johnson replies that although the problem motivating the definition is in a sense semantical, it is not "just semantics" in the sense of being unimportant. In the course of his reply, Johnson probably admits too much when he concedes some force to this objection and declares that his conception is a stipulative definition. For as Hansen (2002, 272-73) has argued and as Johnson himself (2002a, 313-14) later admitted, Johnson's thesis is really a theoretical definition; that is, a claim that is part of a theory of argument aiming to provide concepts and principles for the identification, understanding, interpretation, analysis, evaluation, and criticism of arguments.

Besides these replies to these five objections, contained in the book Manifest Rationality, since the book was published several scholars have advanced other objections and Johnson has replied to them (Govier 1998, 1999b, 2000; Groarke 2002; Hansen 2002; Hitchcock 2002a; Leff 2000; Tindale 2002; Rees 2001; Wyatt 2001 ; cf. Johnson 2002a, 2003). Thus a complete account or an extended discussion of Johnson's argument would have to include these additional objections and 
replies. However, my aim here is theoretical rather than historical, and so my discussion of them here will be guided by their relevance to the problem under discussion, namely the nature and adequacy of the dialectical approach in general vis-à-vis the non-dialectical approach, and in particular the relative merits of the illative and dialectical conceptions of argument.

To begin with, some of objections raised after publication had been anticipated by Johnson. This applies to the objections that his definition is too restrictive, that the dialectical tier is unnecessary, and that the definition is circular. However, needless to say, after the book's publication, new nuances and clarifications have emerged from these discussions.

In regard to other objections, I wish to reiterate something I stated at the beginning of this paper. That is, when I introduced the dialectical conception of argument (section 2), I first gave my own formulation, and then I quoted Johnson's definition as an illustration. I also claimed that in giving my own formulation, I had attempted to incorporate the most important clarifications and most telling objections that had emerged from post-publication discussions. One example will have to suffice.

Both Hansen (2002, 269-70) and Hitchcock (2002a, 289) have independently objected that Johnson's definition, as he words it, states or implies that to be an argument (at least in the paradigm sense of the concept) a discourse must contain all (and not just some of) the reasons that support the conclusion; plus only those reasons that actually support it, as contrasted to those that are intended to support it; plus replies to all objections and criticisms, and not just to some; and only actual replies, rather that attempted replies. Thus, they have suggested that when Johnson says that an argument presents "the reasons that support it [the conclusion]" (Johnson 2000a, 168) the definition should instead speak of "reasons in support of the conclusion" or "reasons that attempt to support the conclusion." And when he says that in the argument's dialectical tier "the arguer discharges his dialectical obligations" (Johnson 2000a, 168), the definition should instead say that the arguer attempts to discharge some dialectical obligations.

These revisions also take care of the infinite-regress objection advanced by Govier (1998, 8; 1999b, 232-37). This is the objection that if all arguments must have a dialectical tier, then a reply to an objection must also have a dialectical tier, since such a reply is or should be an argument; thus, a reply to an objection to the original conclusion must contain replies to the objections to the reply, and so on ad infinitum. Johnson's best reply to this objection involves "pointing out the parallel between the illative core and the dialectical tier. That is, the same line of reasoning that prevents an infinite regress in the illative core can also be deployed to prevent the exfoliation of the dialectical tier" (Johnson 2003, section 3a).

Johnson does not elaborate. I suppose what he has in mind is the following traditional difficulty: if an argument must have an illative tier containing "the" reasons that support the conclusion, it must contain not only all the reasons that 
directly support it (which is already an indefinitely long process), but it must also contain all the lower-level reasons that directly support those direct reasons and so indirectly support the original conclusion; but such indirect reasons must themselves be supported by further reasons, and so on ad infinitum. This well known infinite regress is usually stopped by saying that the illative tier need contain only those reasons that seem appropriate in the given context.

The situation with the dialectical tier is analogous: one replies only to those objections that seem appropriate in the context. At the level of the formulation of the definition of argument, elimination of the definite article I believe does the trick: if we say that an argument is an attempt at justification which gives reasons in support of a conclusion or defends it from objections, this clearly means that it gives one or more reasons in support of the conclusion and/or defends it from one or more objections.

\section{Conclusion: A Moderately Dialectical Conception}

To recapitulate, Johnson's argument for the dialectical conception of argument is complex and multi-faceted. It has an illative tier that advances at least three supporting reasons: empirical support reminiscent of an inductive generalization; the argument from the nature of the process of arguing; and the argument from the telos of rational persuasion. Johnson's argument also has a dialectical tier consisting of two main parts, criticism of alternatives and replies to objections. He criticizes the traditional conception of argument in at least four ways: that it conceives argument as having structure but no function; that it fails to distinguish argument from other forms of reasoning, especially explanation; that it presupposes an inadequate conception of inference; and that it fails to give an adequate account of the dialectical nature of argumentation. Furthermore, he replies to at least six objections that allege the following charges: excessive narrowness of scope, dispensability of the dialectical tier, vicious circularity, lack of novelty vis-à-vis Toulmin, triviality beyond semantical issues, and infinite regress.

In light of this interpretation, reconstruction, and analysis of Johnson's argument, it is obvious that it satisfies its own definition. And given the stringent requirements of this definition, this satisfaction represents a considerable merit. In the course of my discussion, I have also assessed, evaluated, and criticized that argument. It would be too tedious to recapitulate these assessments, but it is important to point out that they have been partly negative, unfavorable, and destructive, and partly positive, favorable, and constructive. That is, they have been partly critical (in the ordinary sense of criticism connoting negativity), and partly critical in Johnson's (2000a, 217-23) own sense (connoting fruitful constructiveness). To add a further dimension to such constructiveness and to try to provide a synthetic overview of the forest after our long journey through its trees, I would suggest that the upshot of my assessments is that Johnson's argument is cogent insofar as it justifies the following thesis, and implausible otherwise. The thesis is 
the claim that an argument is an attempt to justify a conclusion by giving reasons in support of it or defending it from objections.

I further claim that this is a moderately dialectical conception and that I have provided an argument in favor of this conception. A question now arises. What kind of argument have I provided? Is it self-referentially consistent? That is, does my argument fit my own definition? Is my argument an instance of its own conclusion? I believe it is. It may be viewed primarily as a defense of this moderately dialectical conception by means of criticism of Johnson's alternative strongly dialectical conception. Such a defense would suffice to make it an argument (in the sense of the moderate definition), even though it is obvious that I have not explicitly defended the moderate conception from the other alternatives, namely the hyper dialectical, the illative, the rhetorical, and the purely abstract conception. But I have presumed that in the present context no such defense was needed. If this is correct, this point would further reinforce the moderate conception. On the other hand, my initial remarks about the dialogical model of argument may be seen as an explicit, if summative and sketchy, defense of the same moderate conclusion from the dialogue model.

Moreover, although my moderately dialectical conception of argument does not require every argument to possess an illative tier, my argument may be taken to have such a tier, consisting of two supporting reasons. One is provided by my interpretation, reconstruction, and appropriation of Goldman's truth-in-evidence argument; the other consists of my suggested replacement for Johnson's empirical argument, namely my more systematic version based on the data base from Galileo's Dialogue.

Finally, does my argument include replies to objections? I have already pointed out that the criticism of an alternative can be conceived as a reply to the objection that there is no reason to prefer the given conclusion to the alternative. This link is of course what enables my previous considerations to instantiate the moderately dialectical conception of argument. Furthermore, incidentally and in passing, these considerations also contain replies to possible objections. I would have to admit, however, that so far I have not presented explicit replies to explicit objections. I can also say that I welcome objections, although I do so with some hesitation. In fact, such welcoming leads to a paradox.

The arguer's welcoming of objections is certainly important. And Johnson $(2000 \mathrm{a}, 161,165)$ has written eloquent words in this regard. But if this openmindedness is to be more that a desirable psychological trait, one would have to say that a good argument should elicit objections; indeed that an argument is good (in part) if and insofar as it generates objections. An argument should not fall on dead ears; if it does, more than being a sign of its conclusiveness, it is probably a sign of its sterility. Of course, to be really good, an argument should also have the resources to answer or refute subsequent objections. So it is not really the existence of objections or the possibility of generating them that adds value to an 
argument. It is its ability to elicit refutable, implausible, or invalid objections. It is these that I welcome with open arms.

To encourage this process, I end by volunteering some of these objections myself. The first one may be formulated as follows. It is undeniable that there is a difference between the conjunctive and the disjunctive dialectical conceptions: it is one thing to say that an argument is an attempt to make a conclusion acceptable by means of both reasons in support of it and replies to objections; and it is another to say that an argument is an attempt to make a conclusion acceptable by means of either reasons in support of it or replies to objections. But this is a very small difference: sub specie aeternitatis, they are both dialectical conceptions; and even in the less Olympic earlier presentation of various conceptions of argument, both of these conceptions were treated as special cases of the dialectical conception and were regarded as having much more in common than they had differences, especially vis-à-vis the various versions of the traditional conception. So it is unclear what all the fuss is about; the difference is so minor as to approach triviality.

My reply to this objection is that even the eternal gods who view these matters from Olympus need to cultivate their powers of discrimination and their ability to make fine distinctions. So there is no good reason to ignore the difference between conjunction and inclusive disjunction. The important point is that differences should not be magnified or exaggerated, but the other side of this coin is that they should not be minimized or underplayed. However, such balance has been precisely what I have stressed in this essay, by beginning to point out that these two definitions were versions of the dialectical approach, and by ending with the conclusion that the disjunctive conception seems to be preferable to the conjunctive one.

A second objection one could raise is a criticism from the point of view of that I have called the hyper dialectical conception. This is the view that an argument is a defense of its conclusion from actual or potential objections. From the point of view of the hyper conception, the moderate definition is a step in a direction opposite to what is needed: presumably one should further strengthen Johnson's strong conception rather than weakening it into the moderate conception. And the important reason to take a step toward the hyper conception is the following: given any claim that has been asserted, one could always raise the question, what reasons if any there are in support of the claim. This question may be regarded as the prime or minimal objection to any claim. If one anticipates it, one constructs the illative tier and gives the supporting reasons even before the objection has actually been raised. Or one can wait until after the objection has been explicitly raised. In either case, the illative component can be interpreted as a part of the dialectical tier.

To answer this objection, I would begin by pointing out that if it cannot be satisfactorily answered, then I for one would have no difficulty with revising my conclusion by modifying the moderate into the hyper conception. But before resorting to this revision, I would want to try the following reply. That is, in a way analogous to how this objection attempts to interpret the illative component in 
terms of the dialectical tier, one can perhaps try to do the reverse and reinterpret the dialectical tier in terms of the illative component.

Consider an argument whose illative component consists of premises $\mathrm{P}-1$ though $\mathrm{P}-\mathrm{n}$ and conclusion $\mathrm{C}$. And suppose the argument also has a dialectical tier with objections $\mathrm{O}-1$ through $\mathrm{O}-\mathrm{k}$, respectively answered by replies R-1 through R-k. Now consider the conjunction of an objection and its corresponding reply, $(\mathrm{O}-\mathrm{j} \&$ $\mathrm{R}-\mathrm{j}$ ), or some appropriately reworded phrasing of it that might be needed for grammatical propriety. It seems to me that such a conjunction would constitute a reason supporting the conclusion $\mathrm{C}$. It would be like saying that one reason for accepting the conclusion is that if one objects to it in such and such a way, such an objection would be incorrect; or collectively considered, one reason for accepting conclusion $\mathrm{C}$ is that all objections against it fail, i.e. that there are no objections to it. In other words, an objection to a conclusion $\mathrm{C}$ may be seen as a reason against it, a reason for claiming not- $\mathrm{C}$; and if a reason $\mathrm{R}$ for not- $\mathrm{C}$ is a bad reason, then the claim that $\mathrm{R}$ is a bad reason for not- $\mathrm{C}$, may be seen as a reason for $\mathrm{C}$. Of course, such a reason would not be a conclusive reason, and to claim such conclusiveness would be to commit a damaging version of the fallacy from ignorance; indeed I have already suggested that for conclusiveness or deductive validity, the question of objections does not even arise. But we are clearly dealing with reasons that, however strong, fall short of conclusiveness, and for such cases the explicit refutation of an explicit objection may be viewed as a supporting reason.

The upshot of these considerations is that while the presentation of supporting reasons may be regarded as a reply to a weak or minimal objection, the refutation of objections may be regarded as a weak or minimal supporting reason. There thus seems to be symmetry between the illative and the dialectical tiers, and this is perhaps another reason for giving them separate mention in the definition of argument, as the disjunctive conception does.

A third objection to my argument involves Johnson's notion of manifest rationality, by which he means the attempt to not only be rational, but also to look and appear rational. The objection would allege that in my reconstruction of his argument I have ignored the following element of its illative tier: that an argument must have a dialectical tier because "argumentation [is] more than just an exercise in rationality" (Johnson 2000a, 163), it is also an exercise in manifest rationality; and "manifest rationality is why the arguer is obligated to respond to objections and criticisms from others" (Johnson 2000a, 163-64). This argument is hard to miss since it is being referred to in the title of Johnson's book; since it is given in the body of the work when the idea of manifest rationality is explicitly discussed (Johnson 2000a, 163-64); and since elsewhere (Johnson 2000b, 3) he explicitly presents it as an additional line of justification, besides the argument from the telos of rational persuasion. Moreover, the argument is apparently important because if it were cogent it would justify the strongly dialectical conception of argument, but not the moderate definition. 
My response to this objection starts with a criticism of the argument from manifest rationality. In regard to its premise that argument is an exercise in manifest rationality, it may be deemed acceptable, but I do wonder whether its acceptability exceeds that of the conclusion. Moreover, I agree that the premise is more or less relevant, but I question whether it is sufficient. One reason for questioning its sufficiency is that, as we saw in the case of the argument from the telos of rational persuasion, an additional interdependent premise is needed, namely a proposition about the controversial origin of argumentation; otherwise, as proofs in Euclidean geometry suggest, rationality can be achieved without replying to objections.

A more specific and important reason for questioning the sufficiency of the present premise of manifest rationality is that it is unclear that it really adds anything to the argument from the telos of rational persuasion. Johnson's key point here seems to be that whereas rationality as such might be taken to require that one answer only objections that are really relevant, manifest rationality requires that one answer objections that appear to be relevant, even if in reality they are not. But I would point out that the inclusion of apparent, as distinct from real objections, is required by the telos of rational persuasion, for it would not be persuasive to neglect objections that are believed (even if incorrectly) to be forceful. In other words, in Johnson's own account the two operative notions are manifest rationality and rational persuasion, and these seem to me to be two sides of the same coin, rather than two distinct concepts. Although similar considerations have led Hitchcock and Hansen to conclude that Johnson's notion of manifest rationality is rhetorical after all, my own conclusion here is that this argument from manifest rationality has no force above and beyond the argument from the telos of rational persuasion.

There is another conclusion I would want to draw. I originally did not include this supporting reason in my reconstruction of the illative tier of Johnson's argument because 1 judged it to be devoid of the additional force just mentioned. In doing so, I was operating, I believe, from the point of view of strict rationality, as distinct from manifest rationality. I was telling myself that, appearances to the contrary, and despite Johnson's own explicit statements to the contrary, he really had no distinct argument; so also using the principle of charity, I decided it was better to neglect these considerations, rather than interpreting them as an argument and then criticizing the argument as worthless. In that sense and to that extent, my previous neglect was justified, and hence the present objection has no force.

However, in discussing this objection now, I was taking the point of view of manifest rationality at the metalevel. That is, given all the appearances (at the object level) that manifest rationality is one of Johnson's reasons in support of the dialectical tier, I explored whether these appearances correspond to reality; whether this reason, besides being meant to support his conclusion, does really support it. If and insofar as my doing so has added to the persuasive force of my own 
argument, then perhaps I have come closer to achieving my present aim of rationally persuading you that the moderate conception is preferable. Furthermore, such rational persuasion has perhaps been enhanced by the fact that I explicitly included at least one objection which for me did not have even prima facie plausibility, but which might be plausibly advanced by Johnson or anyone taking his point of view; and this in turn may be taken to enhance the practical value of manifest rationality, practical in the sense of the practice of argumentation, even if it remains true, as 1 would hold, that theoretically speaking manifest rationality is an aspect of rational persuasion.

A final objection now comes to mind. It is one from the point of view of the illative conception, and it is based on my criticism of Johnson's criticism of this conception. That is, if it is inaccurate to object, as Johnson does, that the illative conception lacks a teleological aspect and fails to attribute a telos to argument; and if it is inaccurate or unfair to object that the illative conception fails to properly distinguish between argument and other forms of reasoning such as explanation and inference; and if it is circular to object that the illative conception ignores the dialectical nature of argument; then does it not seem that the illative conception can survive Johnson's criticism, and is perhaps adequate? In other words, even if my critique of Johnson's illative tier and of his explicit replies to explicit objections shows that my moderate conception is preferable to his strong one, it does not show that the moderate conception is superior to the illative definition, especially when we recall my criticism of Johnson's criticism of the illative conception. Does not my argument need one other component, namely a criticism of the alternative illative position?

Part of my answer to this objection lies in stressing two arguments discussed earlier: my reconstruction or appropriation of what 1 have called Goldman's truthin-evidence argument and of what I have called Johnson's empirical inductive generalization. Insofar as they support my moderate version of the dialectical conception, they do not support the illative conception. I would also want to exploit my claim about the symmetry of the illative and dialectical tiers; insofar as that claim is correct, it suggests that even if the illative conception were otherwise acceptable, the moderately dialectical re-description of the situation would be more encompassing and therefore better.

And this suggests that perhaps the best line of defense here is to question whether the illative definition of argument is really an alternative to the moderately dialectical conception. One reason to see that they are not really alternatives is to stress that the moderately dialectical definition as I phrased it and an defending it here at the end of my discussion speaks of justification rather than persuasion. This is a revision of the dialectical conception required by the difficulties that emerged when I discussed Johnson's argument from the nature of the process of arguing; that argument could not be regarded as a successful attempt at persuasion (since from the point of view of persuasion it may be begging the question), 
but it was better regarded as a justification (insofar as it is an analytical conceptual elucidation in the context of theorizing). This move from persuasion to justification raises the question of the precise relationship between these two notions, but this issue cannot be elaborated here; suffice it to say that I conceive justification partly as a weakening of the notion of proof, and partly as a requirement for rational persuasion. Thus my moderate conception incorporates an element of the illative definition.

To be sure they are not identical, but they are not inconsistent either. In a sense, the illative conception entails the moderately dialectical one, since the latter is a disjunction of which the former is the first disjunct. But although this entailment ensures their formal consistency, it perhaps points in a misleading direction because it suggests that the moderate conception is a special case of the illative one, whereas the opposite is more nearly correct. That is, the moderate conception is more general than the illative one, in the sense that it can subsume under itself all the particular instances that the illative conception subsumes, plus others that the illative conception does not subsume. If then, the proper relationship between the moderately dialectical and the illative conceptions is not one of competition or inconsistency, but rather compatibility or species and genus, then in arguing for the moderately dialectical conception one need not reject the illative definition, but one should rather incorporate it.

In short, the moderately dialectical conception of argument may be seen as a synthesis of the illative conception and of the strongly dialectical definition. And if the latter two alternatives are dubbed thesis and antithesis, then I may be allowed to end my analysis on this dialectical note. Of course such an ending is dialectical in a sense that is perhaps not in accordance with some people's idea of dialectics, but it is nevertheless suggestive of further work needed to clarify the meaning of the concept of dialectics.

\section{References}

Angeles, P. A. 1981. Dictionary of Philosophy. New York: Barnes \& Noble.

Barth, E. M. 1985. "A New Field: Empirical Logic," Synthese 63: 375-88

Barth, E. M., and E. C. W. Krabbe. 1982. From Axiom to Dialogue, Berlin: Walter de Gruyter.

Barth, E. M., and J. L. Martens, eds. 1982. Argumentation: Approaches to Theory Formation. Amsterdam: John Benjamins.

Blair, J. A. 1995. "Premise Adequacy." In Eemeren et al. (1995a, 191-202).

Blair, J. A. 1998. "The Limits of the Dialogue Model of Argument." In Hansen et al. (1998).

Blair, J. A., and R. H. Johnson. 1987. "Argumentation as Dialectical." Argumentation 1: $41-56$. 
Carnap, R. 1950. Logical Foundations of Probability. Chicago: University of Chicago Press.

Cattani, A. 2001. Botta e risposta: L'arte della replica. Bologna: II Mulino.

Copi, I. 1968. Introduction to Logic. $3^{\text {rd }}$ ed. New York: Macmillan.

Copi, I., and C. Cohen. 1994. Introduction to Logic. $9^{\text {th }}$ ed. New York: Macmillan.

Cummings, L. 2002. "Hilary Putnam's Dialectical Thinking: An Application to Fallacy Theory," Argumentation 16: 197-229.

Eemeren, F. H. van, ed. 2002. Advances in Pragma-Dialecics. Newport News, VA: Vale Press; Amsterdam: SicSat.

Eemeren, F. H. van, and R. Grootendorst, 1992. Argtmentation, Communication, and Fallacies: A Pragma-Dialectical Perspective. Hillsdale, NJ: Lawrence Erlbaum Associates.

Eemeren, F. H. van, R. Grootendorst, J. A. Blair, and C. Willard, eds. 1995a. Analysis and Evaluation: Proceedings of the Third ISSA Conference on Argumentation, vol. 2. Amsterdam: SIC SAT.

Eemeren, F. H. van, R. Grootendorst, J. A. Blair, and C. Willard, eds. 1995b. Perspectives and Approaches: Proceedings of the Third ISSA Conference on Argumentation, vol. 1. Amsterdam: SIC SAT

Eemeren, F. H. van, R. Grootendorst, S. Jackson, and S. Jacobs. 1993. Reconstructing Argumentative Discourse. Tuscaloosa: University of Alabama Press.

Epstein, R. L. 2002. Critical Thinking. $2^{\text {nd }}$ ed. Belmont, CA: Wadsworth.

Findlay, J. 1964. Hegel: A Re-examination. New York: Humanities.

Finocchiaro, M. A. 1980. Galiteo and the Art of Reasoning: Rhetorical Foundations of Logic and Scientific Method. Boston: Reidel [Kluwer].

Finocchiaro, M. A. 1988. Gramsci and the History of Dialectical Thought. Cambridge: Cambridge University Press.

Finocchiaro, M. A. 1994. "Two Empirical Approaches to the Study of Reasoning," Informal Logic 16:1-21.

Finocchiaro, M. A. 1995. "The Dialectical Approach to Interpretation and Evaluation." In Eemeren et al. (1995b, 183-95).

Finocchiaro, M., trans. and ed. 1997. Galileo on the World Systems: A New Abridged Translation and Guide. Berkeley: University of California Press.

Finocchiaro, M. A. 1999. "A Critique of the Dialectical Approach, Part II." In Proceedings of the Fourth International Conference of the International Society for the Study of Argumentation, ed. F. H. van Eemeren, R. Grootendorst, J. A. Blair, and C. A. Willard, pp. 195-99. Amsterdam: SIC SAT.

Freeman, J. B. 1991. Dialectics and the Macrostructure of Arguments. Berlin: Foris Publications.

Goldman, A. 1999. Knowledge in a Social World. Oxford: Clarendon Press.

Govier, T. 1989. "Critical Thinking as Argument Analysis," Argumentation 3: 115-26.

Govier, T. 1998. "Arguing Forever? Or: Two Tiers of Argument Appraisal." In Hansen et al. (1998).

Govier, T. 1999a The Philosophy of Argument. Newport News, VA: Vale Press. 
Govier, T. 1999b. "Progress and Regress on the Dialectical Tier." In Govier (1999a, 22340).

Govier, T. 2000. "Critical Review: Johnson's Manifest Rationality," Informal Logic 20: 281.91.

Groarke, L.. 2002. "Johnson on the Metaphysics of Argument," Argumentation 16:277286.

Hansen, H. V. 2002. "An Exploration of Johnson's Sense of "Argument'," Argumentation 16: 263-76.

Hansen, H. V., C. W. Tindale, and A. V. Colman, eds. 1998. Argumentation and Rhetoric. St. Catharines, ON: Ontario Society for the Study of Argumentation. CD. ISBN: 0$9683461-0-3$.

Hansen, H. V., C. W. Tindale, J. A. Blair, R. H. Johnson, and R.C. Pinto (eds.). 2002. Argumentation and Its Applications. Windsor, ON: Ontario Society for the Study of Argumentation. CD.

Hempel, C. 1965. Aspects of Scientific Explanation. New York: Free Press.

Hitchcock, D. 2002a. "The Practice of Argumentative Discussion," Argumentation 16: 287-98.

Hitchcock, D. 2002b. "Sampling Scholarly Arguments: A Test of a Theory of Good Inference." In Hansen et al. (2002).

Johnson, R. H. 1996. The Rise of Informal Logic. Newport News, VA: Vale Press.

Johnson, R. H. 1998. "Response to Govier's 'Arguing Forever? Or: Two Tiers of Argument Appraisal"," In Hansen et al. (1998).

Johnson, R. H. 2000a. Manifest Rationality: A Pragmatic Theory of Argument. Mahwah, NJ: Lawrence Erlbaum Associates.

Johnson, R. H. 2000b. "More on Arguers and Dialectical Obligations." In Tindale et al. (2000).

Johnson, R. H. 2002a. "Manifest Rationality Reconsidered: Reply to My Fellow Symposiasts," Argumeniation 16: 311-31.

Johnson, R. H. 2002b. "More on Arguers and Their Dialectical Obligations." In Hansen et al. (2002).

Johnson, R. H. 2003. "The Dialectical Tier Revisited." In F.H. van Eemeren, J.A. Blair, C.A. Willard and A.F. Snoeck Henkemans, eds., Proceedings of the Fifth Confer. ence of the International Society for the Study of Argumentation, 561-566. Amsterdam: SicSat.

Kalish, D., and P. Montague. 1964. Logic: Techniques of Formal Reasoning. New York: Harcourt, Brace \& World.

Krabbe, E. C. W. 1998. "Comment on J. Anthony Blair's Paper." In Hansen et al. (1998).

Krabbe, E. C. W. 2000. "In Response to Ralph H. Johnson's 'More on Arguers and Dialectical Obligations." In Tindale et al. (2000).

Krabbe, E. C. W. 2002. "Profiles of Dialogue as a Dialectical Tool." In Eemeren (2002, 15367).

Leff, M. 2000. "Rhetoric and Dialectic in the Twenty-first Century," Argumentation 14: 241-54. 
Mill, J. S. 1965. Essential Works. Ed. M. Lemer. New York: Bantam Books.

Perkins, D. N. 1989. "Reasoning as It Is and as It Could Be: An Empirical Perspective." In Thinking Across Cultures: The Third International Conference on Thinking, ed.

D. N. Topping, D. C. Crowell, \& V. N. Kobayashi. Hillsdale, NJ: Lawrence Erlbaum Associates.

Perkins, D. N., R. Allen, \& J. Hafner. 1983. "Difficulties in Everyday Reasoning." In Thinking: The Expanding Frontier, ed. W. Maxwell. Philadelphia: The Franklin Institute Press.

Pollock, J. 1986. Contemporary Theories of Knowledge. Totowa, NJ: Rowman \& Littlefield. Reed, C. 2000. "Building Monologue." In Tindale et al. (2000).

Reed, C., and D. Long. 1998. "Persuasive Monologue." In Hansen et al. (1998).

Rees, M. A. van. 2001. "Review of Johnson's Manifest Rationality," Argumentation 15: 231-37.

Rowland, R. C. 1987. "On Defining Argument," Philosophy and Rhetoric 20: 140-59.

Scriven, M. 1976. Reasoning. New York: McGraw-Hill.

Skyrms, B. 1966. Choice and Chance: An Introduction to Inductive Logic. Belmont, CA: Dickenson.

Snoeck Henkemans, A. F. 1992. Analysing Complex Argumentation. Amsterdam: SICSAT. Tindale, C. 2002. "A Concept Divided: Ralph Johnson's Definition of Argument," Argumentation 16: 299-309.

Tindale, C., H. V. Hansen, and E. Sveda, eds. 2000. Argumentation at the Century's Turn. Ontario Society for the Study of Argumentation. CD. ISBN: 0-9683461-1-1.

Toulmin, S. 1958. The Uses of Argument. Cambridge: Cambridge University Press.

Turing, A. M. 1950. "Computing Machinery and Intelligence," Mind 59: 433-60.

Walton, D. 1990. "What is Reasoning? What is an Argument?" Journal of Philosophy 87:399-419.

Walton, D., and E. C. W. Krabbe. 1995. Commitment in Dialogue. Albany, NY: State University of New York.

Woods, J., and D. Walton. 1989. Fallacies: Selected Papers 1972-1982. Dordrecht: Foris Publications.

Wyatt, N. 2001. "Review of Johnson's Manifest Rationality," Philosophy in Review 21: 185-87.

Maurice A. Finocchiaro Department of Philosophy University of Nevada-Las Vegas Las Vegas, NV 89154 mauricef@ccmail.nevada.edu 